2. To: (Receiving Organization) SST Retrieval Projects

W-320/73532

8. Originator Remarks:

Test Report Approval and Initial Release.
5. Proj./Prog./Dept./Div.:
3. From: (originating organization) SST Retrieval Projects

6. Cog. Engr.:

J. R. Bellomy

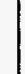

11. Receiver Renarks:
4. Related EDI NO.:

$$
\text { N/A }
$$

7. Purchase order No.:

$$
\text { N/A }
$$

9. Equip./Component No.: W-320 Pump/Winch Assemb1jes

10. System/Bldg./Facility:

241-C-106, 241-AY-102

12. Major Assm. Dwg. No.: W-320-P17, W-320-P24

13. Permit/Permit Application No.: $N / A$

14. Required Response Date: $N / A$

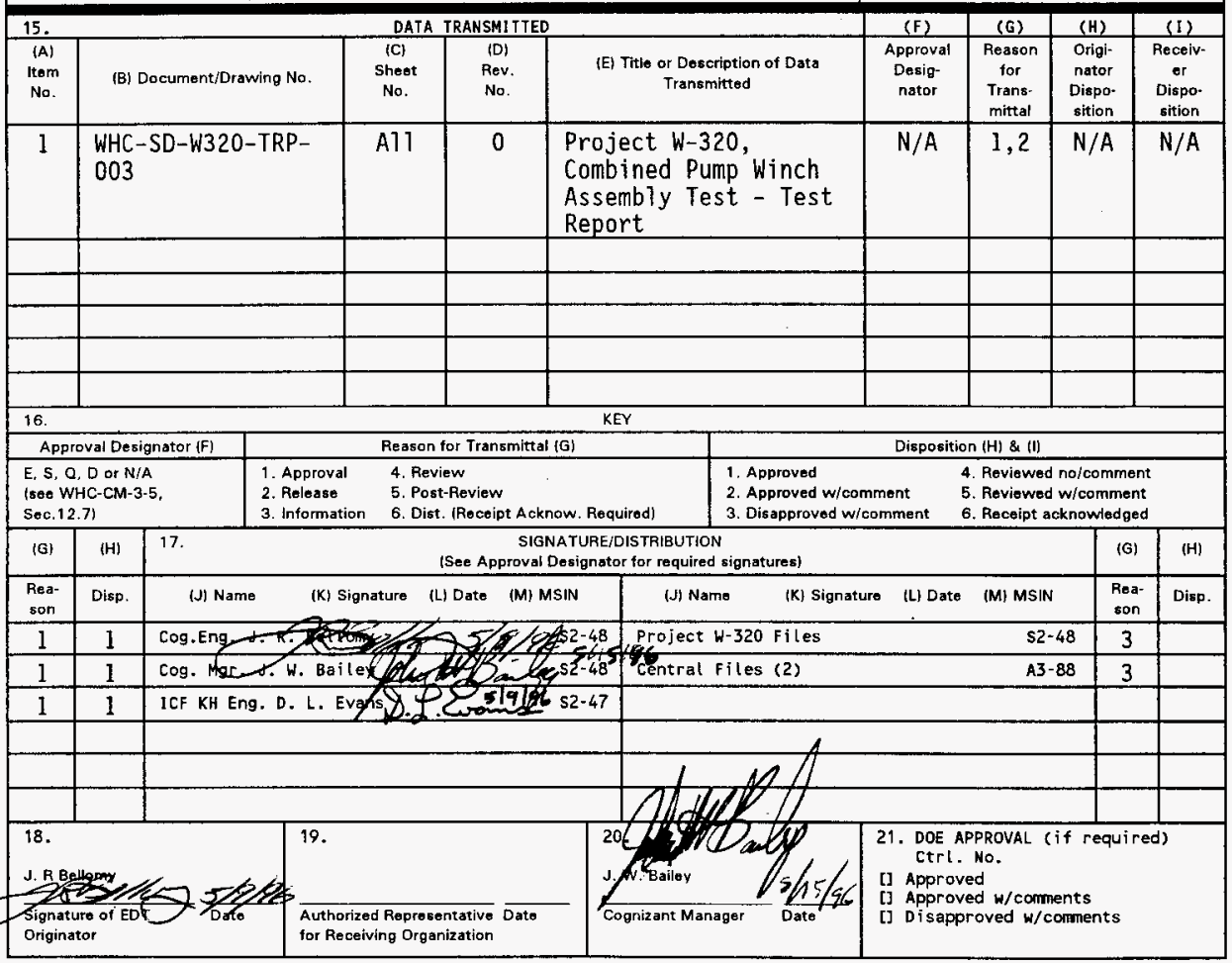




\section{PROJECT W-320, COMBINED PUMP WINCH ASSEMBLY TEST - TEST REPORT}

J. R. Bellomy

Westinghouse Hanford Company, Richland, WA 99352

U.S. Department of Energy Contract DE-AC06-87RL10930

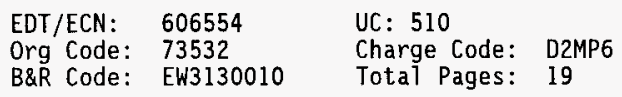

Key Words: 241-C-106, Project W-320, Sluicing, Pump/Winch Test

Abstract: Test Report documenting results of the Project W-320 Combined Pump/Winch Test performed at Lawrence Pumps.

TRADEMARK DISCLAIMER. Reference herein to any specific commercial product, process, or service by trade name, trademark, manufacturer, or otherwise, does not necessarily constitute or imply its endorsement, recommendation, or favoring by the United States Government or any agency thereof or its contractors or subcontractors.

Printed in the United States of America. To obtain copies of this document, contact: WHC/BCS Document Control Services, P.O. Box 1970, Mailstop H6-08, Richland W4 00352 phage (5092 372 2420; Fax (509) 376-4989.
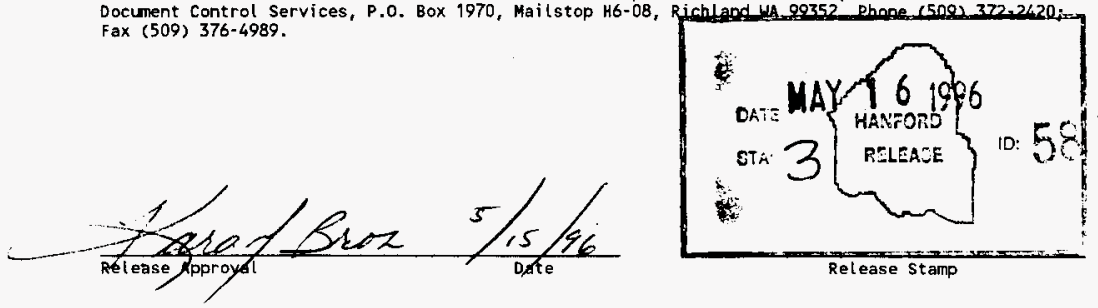

\section{Approved for Public Release}


WHC-SD-W320-TRP-003

Revision 0

\section{Project W-320, Combined Pump Winch Assembly - Test Report}

\subsection{INTRODUCTION}

This test report is prepared to document the results of the integrated testing of the Project $W-320$ winch and immersible pump assembly. Testing was conducted at the Lawrence Pumps facility located in Lawrence, Massachusetts Apri1 18, 1996 through April 20, 1996. Project representatives witnessing testing included J. R. Bellomy (WHC) and D. L. Evans (ICF-KH).

A summary of the combined pump/winch test is provided in the following. Included are background information, test goals and objectives, a brief discussion on the immersible pump 24 hour run-in, a detailed discussion of the combined pump/winch test, and conclusions and recommendations.

\subsection{BACKGROUND}

Project $W-320$ has been established to remove and transport radioactive and chemical sludge from single-shell tank 241-C-106 to double-shell tank 241-AY102. Waste retrieval will be accomplished using past practice sluicing techniques successfully employed in previous tank waste retrieval campaigns.

All equipment, components, and infrastructure necessary to conduct sluicing operations are provided as part of the project (designed, procured/fabricated, installed, and tested). This includes immersible and in-line slurry and siuice pumps, winch assemblies, waste transfer lines, a waste sluicer, a new air processing system at tank 241-C-106, air, water, and fire protection systems at C-Farm, and electrical upgrades at both $\mathrm{C}$ - and $\mathrm{AY}-\mathrm{Farm}$.

Two major components of the sluicing system include the immersible pumps and the winch assemblies. An immersible pump/winch combination will be installed at both tank 241-C-106 and tank 241-AY-102. The pump/winch combinations are virtually identical with the exception of minor variations in linkage lengths to accommodate the differences in the tank pit depths.

The immersible pump will be suspended within the waste tank by the winch assembly and will pump waste from within the tank to the in-line booster pump located in the pump pit of each respective tank. The winch assembly will support the immersible pump within the tank and provide the fluid connection (piping) from the immersible pump to the in-line booster pump. The winch assembly will also provide the mechanical means for remote vertical positioning of the immersible pump while suspended within the tank.

The immersible pumps and the winch assemblies are being fabricated and tested by offsite vendors under separate procurement contracts. The immersible pumps are being fabricated in Lawrence, Ma. by Lawrence Pumps in accordance with Procurement Specification W-320-P17 under Purchase Order 78259. The winch 
WHC-SD-W320-TRP-003

Revision 0

assemblies are being fabricated in Washougal, Wa. by Orbit Industries in accordance with procurement specification W-320-P24 under Purchase Order 82199.

Procurement specifications for the immersible pumps and the winch assemblies require factory acceptance testing of the fabricated equipment to demonstrate compliance with the equipment specifications and verify adequacy of design. Procurement specification $W-320-P 17$, in addition to requiring pump performance testing, was modified by $E C N-W-320-187$ to include requirements for performing a comprehensive test of the combined pump/winch assembly.

Lawrence Pumps was selected as the location for performance of the combined pump/winch test, primarily because of their pump test facility. The test facility includes a 27 foot tall structure with work platforms at 9 foot intervals, above a 15 by 15 foot square, 31 foot deep pit. This provided the ideal location to accommodate integrated testing of the pump and winch assemblies.

To support the combined pump/winch test, Orbit Industries shipped one of the two winch assemblies (Winch $W$-1361) to Lawrence Pumps. Prior to shipment, functional testing of the winch assembly was performed by Orbit Manufacturing using several temporary winch components and a pump mockup.

Temporary components included nylon strap in place of the steel flat cable, carbon steel swivel joints without rotation stops in place of stainless steel swivel joints with rotation stops, a temporary lifting fixture, and a test control panel. The use of temporary winch components in testing was necessary to accommodate project schedules and was justifiable in that temporary components were representative of worst case operating conditions.

The winch assembly was shipped to Lawrence Pumps several days prior to the scheduled combined pump winch test in a partially disassembled condition. Temporary winch components used in winch testing at Orbit Industries (nylon strap, carbon steel swivels, temporary lifting fixture and test pane1) had not been replaced (as anticipated) and were reused for the testing at Lawrence Pumps. The winch position indicator also was not installed as the CPU had not been received by orbit Industries prior to shipment.

The winch position indication system had originally been planned to be checked as part of the combined/pump winch test and appropriate steps had been incorporated in the pump specification for position system verifications by $\mathrm{ECN}-\mathrm{W}-320-187$. However, because the CPU was not included with the winch shipment, ECN-W-320-263 was generated deleting the requirements for verification of the position indicator. This did not compromise testing of the winch assembly as calibration and testing of the winch position indication system was subsequently planned at Orbit Industries following installation of the permanent steel cable. 
WHC-SD-W320-TRP-003

Revision 0

Upon unpacking of the winch assembly at Lawrence Pumps, some damage to the equipment was noted. A nail had been driven through one of the conductors during packaging and the 4 inch stainless steel pipe at the winch support plate was not resting on the support bracket (temporary pipe attachment bracket at the winch plate had been bent). Lawrence Pumps repaired the damage prior to initiation of testing activities, following consultation with ICF-KH Engineering.

\subsection{TEST GOALS AND OBJECTIVES}

The primary objectives of the combined pump (winch test were to: 1) Verify that the immersible pump interfaced properly with the winch assembly during assembly and installation; and 2) Demonstrate that both components were capable of operating as designed under simulated operating conditions.

Specific test goals were as follows:

- Verify assembly and proper interface of the immersible pump with the winch

- Establish means of routing and attachment of pump power and instrumentation cables

- Verify installation and performance swivel joint shrouds

- Demonstrate proper balance and vertical alignment of the pump \winch assembly while suspended from the crane

- Verify the remote installation of combined pump/winch assembly in a 34 inch diameter riser mockup while in the fully retracted position

- Demonstrate the free movement of the winch components throughout the full range of motion

- Demonstrate the capability of the winch assembly to maintain (hold) vertical pump position at various elevations (proper brake action)

- Verify operability of the immersible pump soft start

- Resolve concerns regarding wind up resulting from torque generated during startup of the immersible pump

- Establish minimum pump suction head (submergence) during operation and startup to prevent vortexing

- Demonstrate proper operation of the combined pump/winch assembly while pumping fluid at design parameters 
WHC-SD-W320-TRP-003

Revision 0

- Verify that the immersible pump drains following shutdown.

- Demonstrate the capability of the pump/winch assembly to be remotely removed from the mockup riser in the retracted position

- Refine equipment installation and removal sequence/procedures

- Develop video tapes to support personnel training and the operational readiness review process.

\subsection{IMNERSIBLE PUMP 24 HOUR RUN-IN TEST}

Immersible Pump P-1361 was in the final hour of its 24 hour run-in test upon arrival of the project representatives at the Lawrence Pump Test Facility. Water had been piped directly into the pump suction intake such that the pump and motor were operating totally in air. The pump operated very smoothly with no noted deviation from the performance requirements established in the procurement specification.

At the conclusion of the 24 hour run-in period, upper and lower bearing temperatures and motor winding temperatures were obtained from the internal RTDs using a Volt Ohm Meter. All temperatures obtained were in the desired range and well under alarm setpoints provided by the motor manufacturer.

Temperature readings recorded were as follows:

RTD

Lower Bearing

Upper bearing

Phase A Winding

Phase B Winding

\section{Ohms \\ Resistance}

129

135

141

141
Corresponding

Temperature
Manufacturer Recommended

Alarm Setpoint

\subsection{COMBINED PUMP WINCH TESTING}

At the conclusion of the immersible pump 24 Hour run-in, the immersible pump was removed from the test bench and the combined pump winch assembly test was initiated. Testing was conducted following Lawrence Pump Test Procedure Document Number 91231-1, Combined Pump/Winch Assembly Test (attached). A summary of testing activities is presented in the following. 
WHC-SD-W320-TRP-003

Revision 0

\subsection{Equipment Description and Assembly}

The equipment subjected to testing during the combined pump/winch test included the 241-C-106 Winch Assembly (W-1361), the temporary (prototype) winch 1ifting fixture, the winch test control panel, the 24l-C-106 Immersible Pump (P-136I), and an immersible pump soft starter procured from H\&N Electric to support testing (serial number not obtained). A 34" diameter by 9 foot 6 inch long riser mock-up, representative of the worst case riser configuration to be encountered during equipment installation also was provided to Lawrence Pumps in support of testing.

Prior to the initiation of equipment assembly, all winch components and the immersible pump were staged in the bay area of the test facility. The mockup riser had been previously installed at the 9 foot work platform elevation, and the soft starter and winch controller had been mounted on a rack adjacent to the test pit and connected to power.

The winch components were assembled following instructions suppiied by orbit Industries. During assembly it was assumed that the configuration of the winch swivel joints and fittings had not been modified following winch testing at Orbit Industries. This proved to be a bad assumption, as later on it was discovered that the 45 degree elbow at the intermediate swivel joint had been rotated 180 degrees out of position.

Overal1, the assembly of the winch went fairly smoothly; however; a few problems were experienced. The immersible pump motor had been supplied with lifting extensions which proved to be very difficult to install and for the most part inadequate. The lifting extensions had an interference fit with the motor lifting lugs and had to be hammered into position. Also, because the fit was so tight the attachments were not free to pivot once pinned which caused the winch sheave to be slightly offset.

Another problem which was apparent during the assembly process was the routing of the immersible pump power and control cables. It had originally been planned to route the cables along the winch piping and through a 2 inch diameter hole provided in the winch plate. After studying the geometry, it was the consensus of the test team that the cables would be less likely to interfere with the operation of the winch if they were routed with the safety cable. Accordingly, the power and control cables were taped to the safety cable.

The hole provided in the winch plate for cable penetration was also not large enough to pass all of the pump cables. To accommodate testing, the main power cable was routed through the cable penetration and the instrumentation cables were routed through the winch plate drain hole. 
WHC-SD-W320-TRP-003

Revision 0

Examination of the immersible pump and discussions with the Lawrence Pump representatives revealed some additional design problems with the immersible pump. The problems centered around the level detector assemblies and the pump suction screen.

Upon initial observation of the level detector assemblies, numerous problems were apparent. First, the level detectors were mounted in a location which interfered with the movement of the swivel joints. Second, the level detectors were mounted in a horizontal position such that sludge could easily be trapped in the electrode casing (vendor data recommended mounting in a vertical position to allow drainage). Third, the wires exiting the level detectors were unprotected and exposed. Finally, the lower level detector had been positioned approximately 14 inches above the pump intake (no more than 6 inches was desirable).

The Lawrence Pump representatives indicated that the lower level indicator was positioned at lowest level possible and were reluctant to lower its position because of concerns regarding vortexing. However, after further consideration it was agreed to perform a pump draw down test as part of the combined pump/winch test and relocate the low level detector based on the actual point at which vortexing occurred.

Because of the problems associated with the level detector assembly, the assembly was removed prior to installation of the winch/pump assembly in the test riser. Lawrence Pumps acknowledge the problems and agreed to redesign the assembly pending the outcome of the pump drawdown test.

The final problem which was noted at assembly, pertained to the pump suction screen located at the very bottom of the immersible pump. During assembly of the pump and winch, the Lawrence Pumps project manager noted that the pump suction screen would not carry the load of the pump and suggested that the screen be welded in position following receipt at Hanford (screens were not in place during testing). This presented a problem as the planned operation of the pump could potentially result in the most, if not all of the weight of the immersible pump, being transmitted to the suction screen. Lawrence Pumps agreed to redesign the screen such that it could carry the load of the pumps and requested the specification be appropriately modified to include such a requirement.

\subsection{Installation of the Winch Assembly in the Test Riser and System Startup}

Following assembly, the pump/winch combination was raised with the overhead crane and positioned above the mockup riser at the work platform. The immersible pump was out of position and required lowering a few inches to bring it into the proper retracted position. This was accomplished manually by placing an air wrench on the winch drive nut, depressing the locking plate, and rotating the nut. This procedure proved difficult as the winch had tendency to run away (paying out more cable than desired) during the time 
WHC-SD-W320-TRP-003

Revision 0

required to raise the air wrench off the drive nut such that the locking plate could engage.

About the time the immersible pump retracted position adjustment was completed, Lawrence Pumps received shipment of the swivel shrouds from Orbit Industries. The swivel shrouds were unboxed and installed at each of the swivel joint hose connections. The installation of the swivel shrouds was difficult as insufficient clearance was available for the shroud to clear the pipe and hose at the upper and lower clamping points. Adequate clearance was also not available at the bolt tabs to allow placement of a socket or wrench on the nut/bolt heads. None of the problems encountered with the shrouds were of a nature which precluded installation; however; it was apparent that the design was in need of refinement. In addition to clearance problems, the shrouds also appeared to have a high potential to collect and trap tank waste. This was thought to be a minor problem which could be solved simply by providing drain holes or slots in the shrouds.

Following installation of the shrouds the overall pump/winch assembly was inspected for plumb while suspended from the crane. The immersible pump was not hanging as plump as desired and the winch sheave appeared to be skewed which resulted in a slight twist in the winch cables. The intermediate swivel joint was also hanging in a skewed position such that the swivel joint plane. of rotation and was not parallel or in alignment with that of the other swivel joints. As it appeared that nothing could be done to correct the alignment problems without modification of hardware and none of the problems noted would have any significant influence on component operation, the decision was made to proceed with testing.

Additionally, it was noted that the winch lifting fixture had not been correctly instalied. During assembly it was assumed that the radial spacing of three hook arms on the lifting fixture was symmetrical (positioned at 120 degrees). However, upon studying the configuration and winch assembiy drawings closely, it was determined that the hook arm positions were not radially symmetrical and the lifting fixture had been incorrectly positioned. It should be noted, that it was very difficult to visually determine the proper orientation of the lifting fixture as the difference in spacing was very slight (not obvious) and no markings were present. This condition, although undesirable, also did not create a condition which warranted abandonment of testing.

The pump/winch assembly was then lowered into the mockup riser. This operation went very smoothly and without incident. Considerabie operator attention did have to be provided to the winch control cables and the pump cables during the installation. It should be noted that this was not much of an issue and was overcome in a subsequent installation by wrapping the cables around winch assembly above the winch plate. 
WHC-SD-W320-TRP-003

Revision 0

Once the pump winch assembly was in position within the mockup riser, the winch motor drive assembly was connected to the winch. Cables were then connected to the respective equipment controllers and startup checks were performed. The winch was powered up, proper phase rotation was established, and the operation of the upper limit switches were verified.

An attempt was then made to bump the immersible pump such that proper phase rotation could be established. This proved frustrating as the immersible pump soft starter could not be made to energize the pump. After several calls to the soft start vendor (H\&N Electric), it was determined that the soft starter included provisions for an emergency stop which had to be present for the starter to operate. A jumper was installed at the terminal block for the emergency stop which solved the problem and allowed the starter to operate. The motor was then bumped, checked for proper phase rotation (thought to be clockwise when viewed from above, later found to be counter clock wise when viewed from above) and allowed to operate momentarily in air.

\subsection{Combined Pump Winch Test}

Following startup checks the immersible pump was lowered into the pit. As the pump was lowered the intermediate swivel rotated in the wrong direction. The pump was raised and relowered while applying a manual force to rotate the swivel in the proper direction. The pump was then lowered to the fully extended position.

During the lowering of the pump considerable noise from the winch was observed. Upon further operation and evaluation of the noise it was noted that even though the interface had been lubricated, the socket on the winch drive nut was wearing into the locking plate. This was determined to be an unacceptable condition, as long term operation would eventually result in the socket wearing through the locking plate, eliminating the lock.

Also, as the pump was lowered, the lower hose kinked radically and did not display the same action as observed in previous testing conducted at Orbit Industries. The winch drawings and the video tapes of the testing at orbit Industries were carefully reviewed and it was determined that the 45 degree elbow at the intermediate swivel joint was 180 degrees out of position. No explanation could be offered as to how or why the 45 degree elbow was in the improper position, although a minor discrepancy with the drawing was discovered which could have contributed to the misorientation.

Because the 45 degree elbow was in the wrong position, the decision was made to discontinue testing, remove the pump winch assembly from the mockup riser, properly position the 45 degree elbow, and resume testing from the start.

However, since the discharge piping from the winch had already been connected it was decided to first attempt initial operation of the immersible pump while suspended from the winch. 
WHC-SD-W320-TRP-003

Revision 0

With the pump in the fully extended position, the pit was filled with water to a point where the pump motor was completely submerged. The pump was then started with the soft starter set at 5 seconds. After approximately 30 seconds of operation no liquid pumping was observed. Following a short evaluation of the circumstances, it was determined that the motor rotation was in the wrong direction. Two of the motor power conductors were switched at the soft starter and the motor was restarted with the proper rotation (visible motor rotation in the counter clockwise direction when viewed from above). The startup torque of the motor resulted in an approximate 90 degree rotation of the pump which was about what had been anticipated. The pump operation was very smooth and no problems were noted.

Following operation of the pump, the pump was raised to the retracted position using the winch assembly. During raising of the pump, the power/control cable assembly swung between the swivel shroud and the motor casing. This condition did not impair operation of the winch assembly but was a concern as it appeared to have potential to cause damage to the cables.

Once the pump/winch assembly was in the retracted position, power and control cables were disconnected and the winch drive assembly was removed. Power and control cables were wrapped around and tied to the winch gear box. The winch/pump assembly was then removed from the mockup riser using the overhead crane without incident. The swivel shrouds proved to be very effective and solved all problems experienced at orbit Industries during removal. No problems were noted during the removal process.

The pump/winch assembly was positioned on the floor of the test facility and several adjustments were made. The 45 degree elbow was rotated 180 degrees to the proper position and the safety cable was disconnected at the winch plate and twisted approximately three revolutions in a counter clock wise direction such that the cable bundle looped away from the winch piping and swivels. Additionally, the motor 1 ifting brackets were removed and rotated 180 degrees slightly shifting the center of gravity of the pump due to the eccentric design of the motor lifting extensions and the winch lifting fixture was properly positioned on the winch plate.

While the winch assembly was removed for the adjustments, the pump/winch combination was inspected to verify that the assembly was free draining. No signs of trapped water were observed during the disassembly required to perform the adjustments.

Following the adjustments, the pump winch assembly was positioned above the mockup riser and lowered into position. Wrapping the control cables around the gear box completely eliminated problems encountered in the previous installation. The balance and plumb of the pump/winch assembly was also improved by the adjustments. Overall, the installation went very smoothly and was accomplished with virtually no operator assistance. Adequate clearance was maintained at all times and no problems were noted. 
WHC-SD-W320-TRP-003

Revision 0

The winch motor drive mechanism was then connected to the winch and the winch and pump power and control cables were connected. Following startup checks the immersible pump was lowered into the fully extended position using the winch assembly. The rotation of the 45 degree elbow into the proper orientation resulted in the swivels rotating in the proper direction, as expected. The intermediate swivel was still was oriented in a skewed position approximately 30 degrees out of the desired plane of action. This had a tendency to restrict the motion of the intermediate swivel and the swivel at the pump flange due to the undesirable forces acting on the swivel face. This did not result in a serious problem, however it did contribute to some minor kinking of the hose in the lower pump positions. It also effected radial positioning of the immersible pump both prior to, during, and following startup.

With the pump in the fully extended position the pit was filled with water until the motor was totally submerged. The pump was then started and allowed to evacuate the water from the test pit, lowering the liquid level until air was observed entering the intake (as indicated by a reduction in discharge pressure and change in pump sound). The pump performed much better than anticipated and stopped pumping liquid when the water level reach a point at which the pump base plate (suction intake) was submerged approximately onehalf inch. No signs of vortexing were observed.

The liquid level was then raised to a point at which the bottom of the pump was submerged approximately 4 inches. With the pump discharge routed back into the test pit and full flow conditions established, the pump was started, allowed to run a few minutes, and stopped severat times. The pump performance was very impressive and not affected by the wave action created by the return line discharge into the test pit.

The water level of the pit was raised two feet and testing continued in accordance with the test procedure. Beginning with the pump fully extended and submerged 2 feet the pump was started and raised with the winch (while pumping) to a point where the bottom of the pump was submerged approximately 2 inches (gasket between the pump bottom base plate and the bottom of the impeller casing used as reference). Once the pump was at this level the winch was stopped, the pump was shut down, allowed to drain, restarted, and operated for a few minutes. The water level in the pit was then raised two feet and the procedure repeated until the pump had been raised a minimum of 12 feet.

In this phase of testing, no problems were noted with the operation of the pump. The winch also performed its design functions without failure; however; a couple of problems beyond those previously noted were observed. These problems were associated with the winch gear drive/motor assembly, the winch assembly internal drive shaft, and the winch sheave.

Two problems were experienced with the winch gear drive/motor assembly. First, toward the latter part of testing a noise in the instrument cabinet above the motor gearbox was overheard. In tracing a noise it was discovered 
WHC-SD-W320-TRP-003

Revision 0

that the set screws on the belt drive wheel had loosened and/or fell out. This allowed the drive wheel to move up the drive shaft such that it was not in proper alignment with the drive wheels on the resolver and the limit switch mechanism. In addition to being the source of an undesirable noise, it also caused some minor damage to the drive belt.

The second problem noted at the winch gear drive/motor assembly, was a noise emitted from the motor braking mechanism. Trouble shooting of the noise was not pursued as the noise was not discovered until late in testing. The friction type noise sounded as though something had become loose within the brake mechanism. The noise was not thought to be a serious problem but will require further evaluation (to be resolved at orbit Industries).

During operation, the winch assembly internal drive shaft was also noted to have a fairly significant wobble. This was thought to be the source a noise and was determined to contribute to heat detected on the exterior of the winch gear box. The side plate of the winch assembly was removed and the winch was observed while operating under load. Although this problem did not impair operation of the winch assembly, if uncorrected the long term effects could potentially result in detrimental effects to the winch drive mechanism. It was the consensus of the group that the problem could be resolved simply by installing a bearing near the shaft sea?

The final problem noted with the winch assembly, was associated with the sheave assembly. During operation of the winch (primarily while lifting), the sheave assembly emitted a high pitched resonance. This did not affect operation of the sheave however, it was a very annoying undesirable noise. The noise had not been present during winch testing conducted at orbit Industries and was attributed to the skewed orientation of the sheave as sembly.

Testing was concluded by raising the winch to the fully retracted position and shutting down system power. As a final step in testing, accessible components of the pump/winch assembly were inspected for signs of damage. No further signs of damage or problem areas were noted.

The entire test sequence was video tapped by Lawrence Pumps as well as by the members of the project team witnessing testing. Video tapes of testing are available for review and will be retained as part of project files.

\subsection{CONCLUSIONS AND RECOMMENDATIONS}

As a result of testing, it can be concluded that the pump/winch assembly in its present configuration is capable of performing its intended design function. Although several problems were identified, no major problems were discovered which could be considered significant. 
WHC-SD-W320-TRP-003

Revision 0

Several items were noted during testing which will require further evaluation and/or correction. The following actions are recommended prior to

installation of the pump/winch assemblies in the waste tanks.

- Redesign immersible pump level detector assembly to orient detector electrodes in a vertical position, protect wires from damage and el iminate interference with the swivel joints.

- Redesign and/or modify immersible pump motor lifting extensions to provide improved interface with the motor and the winch sheave assembly.

- Revise winch drawings to show routing of winch power and control cables with the safety cables.

- Revise winch drawings or ensure assembly instructions require the winch safety cable be rotated a minimum of three revolutions in the counter clock wise direction prior to attachment to the winch plate.

- Increase the size of the cable penetration hole in the winch plate to accommodate all of the immersible pump cables or revise drawings to reflect routing of control cables through the winch plate drain hole.

- Modify the immersible pump suction screen as required to ensure the screen does not collapse under all anticipated load conditions.

- Modify swivel shrouds to provide adequate clearance at the pipe/hose clamping points and at bolt tabs.

- Modify swivel shrouds to allow drainage of collected liquids.

- Install bearings at sheave assembly to eliminate resonance.

- Install bearing at the socket interface on the winch drive nut locking plate.

- Request Orbit Industries trouble shoot and repair winch motor brake mechanism.

- Install bearing near the shaft seal on the winch assembly drive shaft.

- Perform testing at Orbit Industries using steel pipe in place of upper hose to determine if swivel action and winch operation is improved.

- Evaluate winch sheave/cable orientation to determine if adjustments are possible or feasible to improve orientation.

- Mark or color code winch lifting arms such that proper orientation on the winch plate is easily discernable. 
WHC-SD-W320-TRP-003

Revision 0

- Include requirements in assembly instructions to check torque on the belt drive wheel set screws in the instrument cabinet.

- Following all modifications to the winch assemblies, perform final winch factory acceptance testing using an immersible pump.

ECN-W320-295 has been generated to modify the winch assembly in accordance with the recommendations noted above. Lawrence Pumps has also been directed to proceed with the recommended modifications to the immersible pump.

Following completion of the modifications, the winch assembly will be subjected to a comprehensive performance test at Orbit Industries. To support this testing an immersible pump will be shipped from Lawrence Pumps to Orbit Industries. This testing will serve as a final design verification prior to installation of the pump/winch combination in the waste tank. 
WHC-SD-W320-TRP-003

Revision 0

\section{LLAWRENCE}

PUPS INC.

\section{JOB SPECIFICATION}

Document Number: 91231-1

Revision: 0

Page 1 of 2

Customer: Westinghouse Hanford Company

LPI Shop Order: ER3 1-03-91231

WHC P.O. No.: MZ+XVV.78259

Title: COMBINED PUMP / WIYCA ASSEMBLY TEST

References: (a) Westinghouse Haniord EC. $\#$ W-320-187, dated 1/19/96, Appendix C (pages 10, 11312 ).

(b) ICF Kaiser Haniord Co. Drawing $\#$ H-2-818494, rev. O, (Piping Pump \& Winch Install-C Tank \& Drawing List).

\section{O PURPOSE}

This procedure establishes the combined pump / winch assembly test requirements in accordance with Reterence (a) and (b).

\subsection{SCOPE}

2.1 Testing should be broken up into three sections and should be witnessed and approved by 3 WHC representative.

2.1.1 Combined pump/winch ussembly test, page 10 of ref. (a).

2.1.2 Winch lowering, raising and brake tests, pages 10 and 11 of tez (a).

2.1.3 Pump operation test, pages 11 and 12 of tef. (a).

\subsection{TEST CONDITIONS}

3.1 See reference (a) for test conditions.

4.0 PROCEDURE

4.1 The testing should be pertormed per reference (a).
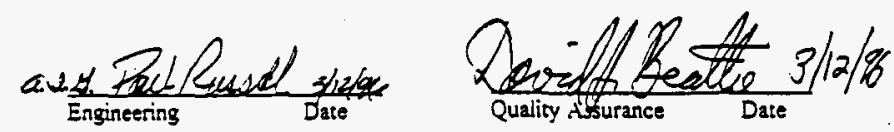
WHC-SD-W320-TRP-003

Revision 0

Document Number: 9123 1-1

Revision: 0

Customer: Westinghouse Hanford Company

LPI Shop Order: EK31-03-91231

Page 2 of 2

WHC P.O. No. MZ4-XVV-78259

\subsection{ACCEPTANCE CRITERIA}

5.I WHC representative will witness and approve all testing and any modifications to the assembly. 
COMBINED PUMPNTNCH ASSEMBLY TEST: The buyer will provide a field representarive to witness and approve all of the below Pump/Winch Assembly testing and any modifications to this assembly. The Seller shail provide as least one week nocice to Buyer betore this testing begins. The Buyer's field representative in consultarion wich the veador will determine what corrective actions, if any, shall be implemented based on the resules of each of the below tests.

1. Assemble Pump/Wiach assembly in accordance with the winch manufacturet's instructions. Balance and veztically align the assegbly (the pump. must hang true vertical = ? in. when fully raised).

2. Install and remove the immmersibie Pump/Winch Assembly in the test riser with the crane operator or signai man viewing only from above. ie., simulate the limited visibility of acrual field instaliacion operations. The installacion/removal operation shall be repeated once to show repeatability. Pump/Winch Assembly shall be in the fully reracted position during instaliation and removal through the test tiser.

3. Moaitor and document any incerterences/problems identitied during this :est.

- 4. Provide aarraive and/or drawing markup recommendations tor modifications of the assembiy to correct any problems ideacified during the test :...............

5. The buyer's represencative shall be tesponsibie for any tield moditication sesuiting from this testing.

6. If moditications are aecessary, repeas the test to verify that the problems have been corrected.

Video - The video taping of this porion of the test should show the following. as a grinimum:

2. Raising the Pump/Winch Assembly into the vertieal position

b. Centering the Pump/Winch Assembly over the riser

c. The botrom end of the pump entering the riser viewed from above

d. The pump coming through the botom of the cest tiser viewed trom below

e. The macing of the winch assembly thange with the test tiser tlange

f. The incerzejion of the PumpiWinch Assembly with the iest riser assembly during the installation and removal process

\section{WINCA LOẄERNG, RAISING AND BRAKE TESTS}

1. After completion of the above tescing. instail the winch drive assembly. elestrical powwer and controls, and initialize the pump position indicator. The test will be conducted with the pump urf. Operate the winch to fully 
WHC-SD-W320-TRP-003

Revision 0

\section{ENGINEERING CHANGE NOTICE CONTINUATION SHEET}

Page 11 of $1 \pm$ Ecy $x-320-187$

lower and raise the pump. During the lowering and raising operasion. the winch will be stopped aear the upper and lower limis of uavel and at approximately the mid point, to verify that the winch brake funcrions properly. At each of these locations, the winch position will be nessured and recorded and the indication system will be checked for accuracy. The cest siall be iepeated at least once to verify repeatability.

2. Monitor and document any interferences/problems identified during this test.

3. Provide aartative and/or drawing markap recommendations for modifieations of the assembly to correct any problems identified during the test.

4. The buyer's representacive shall be responsible for any field modification resulting trom this :esting:

5. If modifications are necessary, tepeat the test to verify that the probtems have been corrected.

Video - The video taping of this portion of the test should show the following, as a minimum:

2. The movement of the hose and pump during the lowering and raising process

b. The stopping of the pump mocion when the winch motor is stopped

PUMPOPERATION TEST

1. Atter the abuve test. complete the installation of the pump electrical (power \& controls) and piping system (Hantord discharge head adaprer. load simulating valve, tlow monitoring squipmenc. and associated piping).

2. Fully extend the Pump Winch Assembly and all the pit to achieve approximately 1 foot depth of submergesce over the pump incake. With the pump in this configuration, star and stop the pump, observe and documeat the $r$ rulting rotacional/windup etteces.

3. Test the pump/winch assembly at 2 foor intervils through the range from fully extended to a point where the pump is raised 12 teet above this level, concurtentiy maincaining the warer level to a 1 foot depth over the pump intake. Surt and stop the pump, observe and document the resulting windup effees at each of these levels. Also record flow data at each of these levels. The winch position will be measured and recorded and the indication system will be checked for accuracy at each of these stop positions.

4. With the pump running, operate the winch assembly through the above range of height adjustment, recording tlow date variteions.

5. Monitor and document any interferences/problems identified during this test. 
WHC-SD-W320-YRP-003

Revision 0

ENGINEERING CHANGE NOTICE CONTINUATION SHEET

Page 12 of $I=\frac{\text { sed } N-320-197}{\text { Jate } 1 / 19 / 96}$

6. Provide nartative and/or drawing markup recommendations tor modifications of the assembly to cortect any problems identified duting the test.

7. The buyer's represeatative sbal! be responsibie for any field modification resulting trom this testing.

8. If modificarions are necessary, repeat the test to verify that the problems have been corrected.

9. Document that the pump is tree draining.

Video - The video aping of this porion of the test should show the following, as a minimum:

2. The movement of the hose and pump during all the staristops of the pump

b. The movement of the winch hose and pump duting the length adjustments

c. The final tull recraction of panp and hose.

d. The removal of Pump/Winch Assembly trom the riser 


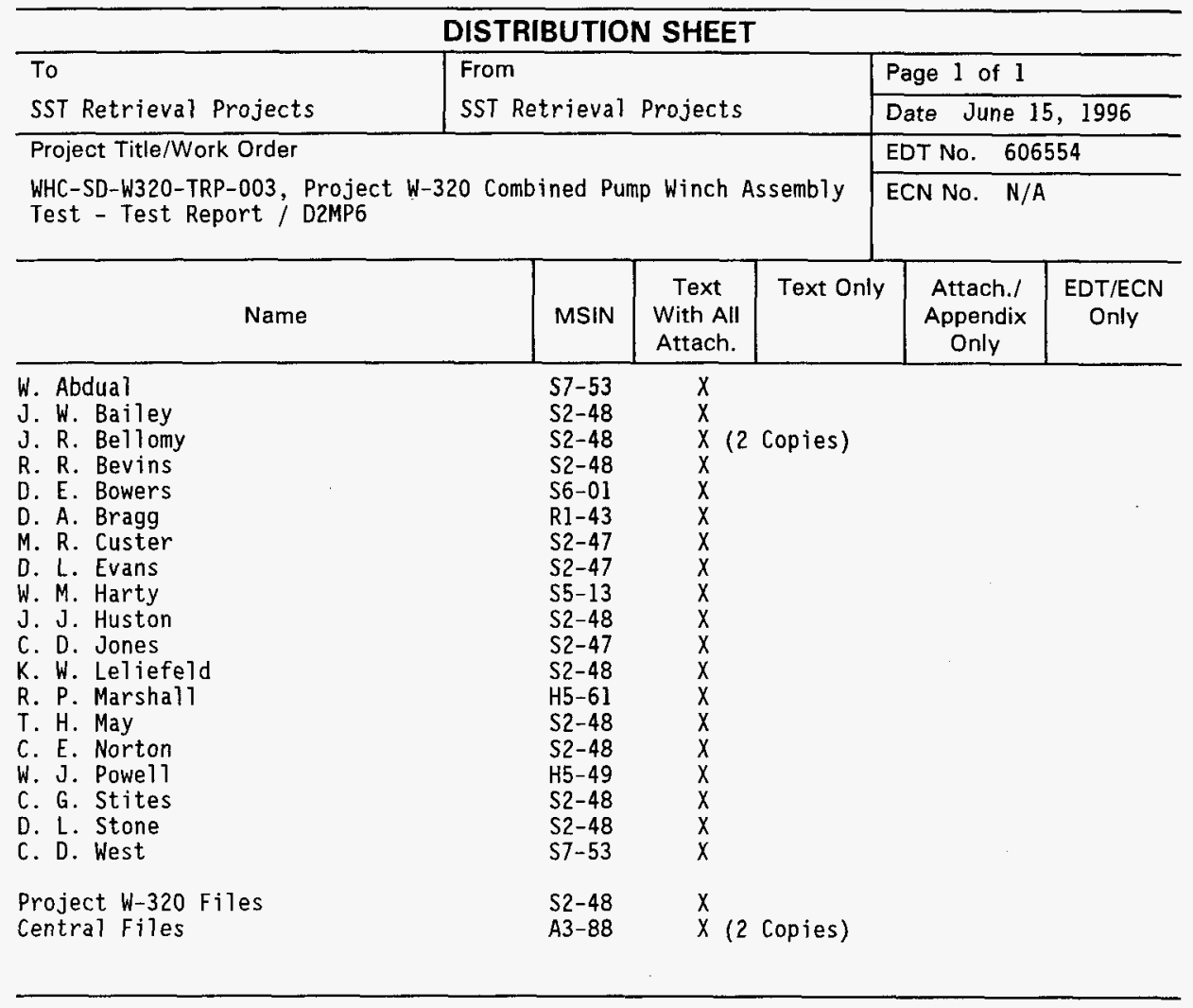

